\title{
Water fluoridation - the public's role in the decision-making process
}

\author{
How much do the general public want to be involved in decisions on implementing water fluoridation? R. J. Lowry \\ B. Thompson, M. A. Lennon, Br Dent J 2000; 188: 500-502
}

\section{Objective}

Test general public view about how much they wish to be involved in water fluoridation implementation decisions.

\section{Design}

Qualitative research using focus group discussions led by an experienced moderator.

\section{Setting}

Among the general public living in three non-fluoridated areas in England.

\section{Subjects}

Members of the public more than 20 years of age and by social class.

\section{Results}

General public wish to be informed of water fluoridation plans but do not see themselves as being the appropriate implementation arbiters.

\section{Conclusions}

In the public's eyes, it would be inappropriate and unwelcome to delegate to them the decision about whether to fluoridate the public water supply.

\section{In brief}

- How much the public should be involved in the implementation of water fluoridation is much debated.

- The public lacks the knowledge to be closely involved.

- They have no desire to be involved in the decision-making process.

- They look to (national) authority figures to shoulder this responsibility.

\section{Comment}

$\Delta s$ we all know, water fluoridation is an A excellent public health measure. It is technically straightforward, brings real health benefits and, perhaps most important of all, delivers these benefits disproportionately to the poor. There are not many magic bullets in this world, but as far as health inequalities are concerned, fluoridation is one.

But it is not happening.

Lowry et al.'s paper begins to tell us why.

It shows that - as survey after survey has shown - the general public continue to support fluoridation, that they want to be kept informed about progress with implementation and reassured that the medical advice, on which this is based, is independent, especially of the water companies. However the paper also shows that they look to health professionals to decide upon and manage implementation; they will not rise up and demand fluoridation and do not feel sufficiently skilled to make final judgements on its efficacy. This confirms and builds on previous research published in this journal. ${ }^{1}$

The researchers used qualitative, focus group procedures. These are ideal for their purpose, which was to probe beyond people's superficial support for fluoridation and see what it means in terms of knowledge, commitment and emotional response to the issue. The last point is particularly important, as we know fluoridation can be very emotive. The methodology also provides a valuable complement to existing research on public attitudes to fluoridation, much of which has been quantitative.

The author's key conclusion is that the public's desire should be met, and health authorities should be empowered to proceed with water fluoridation as quickly and easily as possible. Politicians, they argue, can no longer use the need for public consultation as a means of distancing themselves from hard decisions about fluoridation. The public are saying quite clearly: it is up to you, get on with it.

Given the Government's clear commitment to tackling health inequalities, and fluoridation's capacity to reduce these, surely this call will now be heard.

\section{Professor Gerard Hastings}

Director, The Centre for Social Marketing, University of Strathclyde, Glasgow

1 Hastings G B, Hughes K, Lawther S, Lowry RJ. The role of the public in water fluoridation: public health champions or anti-fluoridation freedom fighters? Br Dent J 1998; 184: 39-41. 